\title{
Utilization of optical remote sensing data and geographic information system tools for regional landslide hazard analysis by using binomial logistic regression model
}

\begin{abstract}
This paper deals with landslide hazard analysis using Geographic Information System (GIS) and remote sensing data for Cameron Highland, Malaysia. Landslide locations were identified in the study area from interpretation of aerial photographs and field surveys. Topographical/geological data and satellite images were collected and processed using GIS and image processing tools. There are ten landslide inducing parameters which are considered for the landslide hazards. These parameters are topographic slope, aspect, curvature and distance from drainage, all derived from the topographic database; geology and distance from lineament, derived from the geologic database; landuse from Landsat satellite images; soil from the soil database; precipitation amount, derived from the rainfall database; and the vegetation index value from SPOT satellite images. Landslide hazard was analyzed using landslide-occurrence factors employing the logistic regression model. The results of the analysis were verified using the landslide location data and compared with logistic regression model. The accuracy of hazard map observed was $85.73 \%$. The qualitative landslide hazard analysis was carried out using the logistic regression model by doing map overlay analysis in GIS environment. This information could be used to estimate the risk to population, property and existing infrastructure like transportation network.
\end{abstract}

Keyword: GIS; Hazard; Landslide; Logistic regression; Remote sensing 